\title{
Sensibilização a alérgenos inalantes e alimentares em crianças brasileiras atópicas, pela determinação in vitro de IgE total e específica - Projeto Alergia (PROAL)
}

\author{
Sensitization to inhalant and food allergens in Brazilian atopic children \\ by in vitro total and specific IgE assay. Allergy Project - PROAL \\ Charles K. Naspitz ${ }^{1}$, Dirceu Solé ${ }^{1}$, Cristina A. Jacob ${ }^{2}$, Emanuel Sarinho ${ }^{2}$, \\ Francisco J. P. Soares², Vera Dantas ${ }^{2}$, Márcia C. Mallozi ${ }^{2}$, Neusa F. Wandalsen², \\ Wellington Borges ${ }^{3}$, Wilson Rocha Filho ${ }^{3}$, Grupo PROAL 4
}

\section{Resumo}

Objetivo: Determinar a freqüência de sensibilização a alérgenos inalantes e alimentares em crianças atendidas em serviços brasileiros de alergia.

Pacientes e métodos: IgE sérica total e específica (RAST) a alérgenos inalantes e alimentares (UniCAP ${ }^{\circledR}$ - Pharmacia) foram determinados em 457 crianças acompanhadas em serviços de alergia pediátrica e em um grupo de controles $(n=62)$. Resultados classe igual ou maior que 1 foram considerados positivos $(R+)$.

Resultados: $A$ freqüência de $R+$ foi significantemente maior entre os atópicos (361/457, 79\%) quando comparados aos controles (16/62, $25,8 \%)$. Não houve diferenças quanto ao sexo. A prevalência de $R+$ entre os atópicos foi significantemente maior para todos os alérgenos avaliados. Os níveis séricos de IgE total foram significantemente mais elevados entre os atópicos com R+ quando comparados aos com R-. Comparando-se atópicos e controles, a freqüência de $R+$ para os principais alérgenos inalantes foi como segue: $D$. pteronyssinus $=66,7$ versus $14,5 \%(p<0,05), D$. farinae $=64,5$ versus $17,8 \%(p<0,05)$, B. tropicalis $=55,2$ versus $19,4 \%(p<0,05)$, barata $=32,8$ versus $9,7 \%(p<0,05)$ e gato $=12$ versus $8,1 \%$. Com os alimentos, observouse: peixe $=29,5$ versus $11,3 \%(p<0,05)$, ovo $=24,4$ versus $4,8 \%(p$ $<0,05)$, leite de vaca $=23,1$ versus $3,2 \%(p<0,05)$, trigo $=20$ versus $8,1 \%(p<0,05)$, amendoim $=14$ versus $4,8 \%(p<0,05)$, soja $=11,8$ versus $4,8 \%(p<0,05)$ e milho $=10,6$ versus $4,8 \%(p<0,05)$. Segundo a idade, os $\mathrm{R}+$ aos alimentares predominaram entre as crianças mais jovens, e o inverso ocorreu com os inalantes.

Conclusões: Nesta população, predominou a sensibilização aos aeroalérgenos, sobretudo aos ácaros domiciliares, e os alimentos foram importantes em crianças mais jovens.

J Pediatr (Rio J). 2004;80(3):203-10: Alergia, alérgeno, IgE, ácaro, alimento.

\begin{abstract}
Objective: To determine the frequency of sensitization to inhalant and food allergens in children seen at Brazilian allergy services.

Patients and methods: Total and specific IgE serum levels to inhalant and food allergens (RAST, UniCAP ${ }^{\circledR}$ - Pharmacia) were measured in 457 children accompanied in pediatric allergy services and in 62 control children age matched. RAST equal or higher than class 1 was considered as positive $(R+)$.

Results: Frequency of $\mathrm{R}+$ was significantly higher among atopics (361/457, 79\%) when compared to controls $(16 / 62,25.8 \%)$. There were no differences according to gender. The frequency of $R+$ to all allergens evaluated were higher among atopics when compared to controls. Significantly higher total IgE serum levels were observed among the atopics with $\mathrm{R}+$ in comparison to those with $\mathrm{R}-$. The frequency of $\mathrm{R}+$ to main inhalant allergens were: $D$. pteronyssinus $=$ $66.7 \% \times 14.5 \%(p<0.05)$, D. farinae $=64.5 \% \times 17.8 \%(p<0.05), B$. tropicalis $=55.2 \% \times 19.4 \%(p<0.05)$, cockroach $=32.8 \% \times 9.7 \%(p$ $<0.05)$, and cat $=12 \% \times 8.1 \%$. In relation to food allergens we observed: fish $=29.5 \% \times 11.3 \%(p<0.05)$, egg $=24.4 \% \times 4.8 \%(p$ $<0.05)$, cow's milk $=23.1 \% \times 3.2 \%(p<0.05)$, wheat $=20 \% \times 8.1 \%$ $(p<0.05)$, peanuts $=14 \% \times 4.8 \%(p<0.05)$, soy $=11.8 \% \times 4.8 \%(p$ $<0.05)$, and corn $=10.6 \% \times 4.8 \%(p<0.05)$. With respect of age, food allergen sensitization predominates in young children whereas the inverse occurs with inhalant allergens.
\end{abstract}

Conclusions: There was a predominant frequency of sensitization to inhalant allergens, mainly house dust mites in the evaluated patients. Food allergens were also responsible for a significant proportion of sensitization, mainly in infants. food.

J Pediatr (Rio J). 2004;80(3):203-10: Allergy, allergen, IgE, mite,

1. Professor titular, Disciplina de Alergia e Imunologia Clínica e Reumatologia, Dep. de Pediatria, Univ. Federal de São Paulo (UNIFESP), São Paulo, SP.

2. Professor adjunto, Disciplina de Alergia e Imunologia Clínica e Reumatologia, Dep. de Pediatria, UNIFESP, São Paulo, SP.

3. Especialista em Alergologia e Imunopatologia, UNIFESP, São Paulo, SP.

4. Grupo PROAL - Luiza Karla de Paula Arruda, Maria Marluce Santos Vilela, Paulo Silva da Silva, Thales Barba, Judith Arruda, Maria Cecília Aguiar, Maria Letícia Chavarria, Antônio Zuliani, Eliana Cristina Toledo, Bruno A. Paes Barreto, Leda Solano de Freitas Souza, Nelson Rosário Filho.

Fonte financiadora: Pharmacia do Brasil (doou kits para dosagens).

Artigo submetido em 015.12.03, aceito em 03.03.04. 


\section{Introdução}

Estudos recentes têm documentado o aumento da prevalência de doenças atópicas em várias partes do mundo. No Brasil, a prevalência de asma, rinite alérgica e eczema atópico foi documentada pela primeira vez como parte de um estudo internacional e revelou ser, em média, 21, 39 e $8 \%$, respectivamente ${ }^{1-3}$. Muitas vezes, essas doenças se iniciam na infância precoce, e seu diagnóstico etiológico nem sempre é facilmente realizado. A presença de anticorpos séricos IgE específicos a alérgenos caracteriza a etiologia alérgica. Esses anticorpos podem ser documentados por testes in vivo ou por ensaios biológicos in vitro.

Os testes cutâneos de hipersensibilidade imediata têm sido a arma mais empregada para identificar in vivo a presença de IgE sérica específica. A escolha dos alérgenos a serem testados é direcionada pela anamnese, e os de maior relevância para uma determinada região devem compor a bateria padrão a ser empregada. Estudos anteriores, realizados em diferentes localidades do Brasil, apontam os ácaros domiciliares Dermatophagoides pteronyssinus, Dermatophagoides farinae e Blomia tropicalis como os principais agentes etiológicos de alergia respiratória ${ }^{4-7}$. No sul do país, os pólens também têm sido identificados como significativos ${ }^{8,9}$.

Embora sejam de fácil execução, os testes cutâneos de hipersensibilidade imediata não são isentos de risco e podem sofrer interferência de vários fatores na sua expressão, o que pode induzir erro de interpretação. Em lactentes, geralmente a expressão da resposta inflamatória alérgica na pele está reduzida ${ }^{10}$, possibilitando uma maior proporção de resultados falso-negativos.

Os testes in vitro buscam identificar a presença de IgE específica no soro dos pacientes e, para tanto, necessitam de substrato ao qual essa imunoglobulina se fixará para ser quantificada. Por serem produzidos fora do país, poderia ser questionado se eles seriam úteis em nosso meio. Entretanto, os epítopos dos alérgenos utilizados são universais e, portanto, utilizados em todos os países. Neste estudo, avaliou-se a presença de IgE sérica específica a alérgenos inalantes e alimentares em uma população de crianças brasileiras atendidas em serviços de alergia de diferentes regiões do país.

\section{Pacientes e método}

Participaram deste estudo caso-controle 457 crianças ( 177 meninas [ $38,7 \%$ ] e 280 meninos [ $61,3 \%$ ]) com idades entre 12 e 144 meses, atendidas em serviços de alergia das cinco regiões do Brasil. As crianças foram distribuídas em cinco faixas etárias, como segue: 1 a 2 anos, 2 a 3 anos, 3 a 4 anos, 4 a 5 anos e 5 a 12 anos. As crianças foram classificadas como atópicas quando apresentavam pelo menos um teste cutâneo de hipersensibilidade imediata positivo (diâmetro médio da pápula igual ou superior a 3 $\mathrm{mm})^{10,11}$ a pelo menos um alérgeno inalante ou alimentar testado no seu serviço de origem, de modo aleatório. Constituíram o grupo controle 62 outras crianças oriundas dos centros de investigação das regiões Nordeste, Sudeste e Sul, com história negativa de doença alérgica e testes cutâneos de hipersensibilidade imediata negativos aos mesmos alérgenos empregados naqueles centros, e que necessitaram colher amostra de sangue por outras causas, como avaliação pré-operatória de cirurgia eletiva ${ }^{10,11}$.

De acordo com a queixa de encaminhamento, os pacientes foram classificados em: lactentes sibilantes $(n=20)$, alergia alimentar $(n=16)$, dermatite atópica $(n=56)$ e alergia respiratória $(n=348)$. Foram definidos como bebês chiadores os lactentes com idade inferior a 2 anos que apresentavam episódios recorrentes de sibilância e em quem outras possíveis causas haviam sido excluídas (síndromes aspirativas, doença fibrocística, malformações do trato respiratório, entre outras). Foram definidos como tendo alergia respiratória os pacientes com asma e/ou rinite comprovadas.

Tanto os pacientes alérgicos quanto os controles foram submetidos a coleta de sangue periférico para determinação dos níveis séricos de IgE específica a alérgenos inalantes (Dermatophagoides pteronyssinus, Dermatophagoides farinae, Blomia tropicalis, gato, cão, fungos, epitélio de vaca, cavalo, gramíneas e baratas) e alimentares (leite de vaca, ovo, amendoim, soja, trigo e painel de peixe) e à determinação dos níveis séricos de IgE total (UniCAP-Pharmacia $\left.{ }^{\circledR}\right)^{12,13}$. Os níveis de $\mathrm{IgE}$ específica (RAST) maiores ou iguais a $0,35 \mathrm{UI} / \mathrm{ml}$ (classe 1) foram considerados positivos ${ }^{13,14}$. O estudo foi aprovado pelos Comitês de Ética, e obteve-se assinatura de consentimento livre pós-informado.

Para a análise das variáveis estudadas, foram empregados testes não-paramétricos, e em todos fixou-se em $5 \%$ o nível de rejeição para a hipótese de nulidade.

\section{Resultados}

Na Tabela 1 observamos a distribuição dos pacientes alérgicos. Como se pode notar, ela foi eqüitativa considerando-se as faixas etárias e as regiões de origem. 0 mesmo ocorreu com relação ao sexo (dados não apresentados). Os controles, por serem em menor número, foram limitados às regiões Nordeste, Sudeste e Sul, e não houve diferenças com relação à sua distribuição por faixa etária: abaixo dos 2 anos = 19,4\%; 2 a 3 anos = 20,9\%; entre 3 e 4 anos $=14,5 \%$; entre 4 e 5 anos $=21,0 \%$; e entre 5 e 12 anos $=24,2 \%$.

A presença de IgE específica a alérgenos inalantes e/ou alimentares foi variável, sendo significantemente menor entre os pacientes alérgicos de baixa idade (Tabela 2). Não foram observadas diferenças entre os pacientes com RAST negativo e os controles nãoalérgicos (Tabela 2).

Os níveis séricos de IgE total variaram muito e, por isso, são apresentados como média geométrica. Eles foram significantemente mais elevados entre os atópicos quando comparados aos controles e aumentaram com o progredir da idade (Tabela 3 e Figura 1). Considerandose a presença ou não de IgE específica a algum dos alérgenos avaliados, a análise desses níveis entre os 
Tabela 1 - Distribuição dos pacientes segundo faixa etária e região

\begin{tabular}{|c|c|c|c|c|c|c|c|c|c|c|}
\hline \multirow{2}{*}{$\begin{array}{c}\text { Faixa etária } \\
\text { (anos) }\end{array}$} & \multicolumn{2}{|c|}{ Total } & \multicolumn{2}{|c|}{ N/NE } & \multicolumn{2}{|c|}{ co } & \multicolumn{2}{|c|}{ SE } & \multicolumn{2}{|c|}{$\mathbf{S}$} \\
\hline & $\mathbf{n}$ & $\%$ & $\mathbf{n}$ & $\%$ & $\mathbf{n}$ & $\%$ & $\mathbf{n}$ & $\%$ & $\mathbf{n}$ & $\%$ \\
\hline$<2$ & 79 & 17,3 & 18 & 13,9 & 12 & 23,1 & 38 & 16,9 & 11 & 21,6 \\
\hline $2-3$ & 83 & 18,2 & 25 & 19,3 & 10 & 19,2 & 40 & 17,8 & 8 & 15,7 \\
\hline $3-4$ & 102 & 22,3 & 27 & 21,0 & 13 & 25,0 & 53 & 23,5 & 9 & 17,6 \\
\hline 4-5 & 81 & 17,7 & 30 & 23,3 & 9 & 17,3 & 33 & 14,7 & 9 & 17,6 \\
\hline $5-12$ & 112 & 24,5 & 29 & 22,5 & 8 & 15,4 & 61 & 27,1 & 14 & 27,5 \\
\hline Total & 457 & 100,0 & 129 & 100,0 & 52 & 100,0 & 225 & 100,0 & 51 & 100,0 \\
\hline
\end{tabular}

N/NE: Norte e Nordeste; CO: Centro-Oeste; SE: Sudeste; S: Sul.

Tabela 2 - Pacientes com IgE sérica específica a alérgenos inalantes e/ou alimentares nas diferentes faixas etárias

\begin{tabular}{|c|c|c|c|c|c|c|}
\hline \multirow{2}{*}{$\begin{array}{l}\text { Faixa etária } \\
\text { (anos) }\end{array}$} & \multirow{2}{*}{$\begin{array}{l}\text { n } \\
\text { total }\end{array}$} & \multicolumn{2}{|c|}{$\begin{array}{l}\text { Alérgicos } \\
\text { IgE específica positiva }\end{array}$} & \multirow{2}{*}{$\begin{array}{c}\text { n } \\
\text { total }\end{array}$} & \multicolumn{2}{|c|}{$\begin{array}{l}\text { Controles } \\
\text { IgE específica positiva }\end{array}$} \\
\hline & & $\mathbf{n}$ & $\%$ & & $\mathbf{n}$ & $\%$ \\
\hline$<2(\mathrm{a})$ & 79 & 50 & 63,29 & 12 & 2 & 16,7 \\
\hline $2-3(b)$ & 83 & 59 & 71,08 & 13 & 3 & 23,1 \\
\hline $3-4(c)$ & 102 & 74 & 72,5 & 9 & 3 & 33,3 \\
\hline $4-5(d)$ & 81 & 68 & 83,9 & 13 & 4 & 30,7 \\
\hline $5-12(e)$ & 112 & 110 & 98,2 & 15 & 4 & 26,7 \\
\hline Total & 457 & 361 & 79,0 & 62 & 16 & 25,8 \\
\hline
\end{tabular}

Partição do qui-quadrado. Diferenças significantes: alérgicos: $a<c, d, e ; b<d, e ; c<e$.

atópicos mostrou que, em todas as faixas etárias, pacientes com RAST positivo $(\mathrm{R}+)$ apresentaram valores de IgE total significantemente mais elevados do que aqueles com RAST negativo. O mesmo ocorreu ao se comparar pacientes $\mathrm{R}+$ com controles (Tabela 3 e Figura 1). A análise comparativa entre os controles e os pacientes com RAST negativo não mostrou diferenças significantes, exceto na faixa de 4-5 anos (Tabela 3 e Figura 1).

A IgE sérica específica a alérgenos inalantes e/ou alimentares foi positiva em 361/457 (79\%) pacientes e em $16 / 62(25,8 \%)$ controles. Na Tabela 4, encontramos a freqüência dos resultados segundo o alérgeno e os grupos estudados. Nela observamos que os alérgenos inalantes, sobretudo os ácaros, foram os de maior prevalência. Entre os alimentos, salientamos: peixe, ovo, leite de vaca e trigo (Tabela 4). Na Tabela 5, são apresentadas as freqüências de positividade para cada um dos alérgenos investigados, distribuídos pelas diferentes faixas etárias, tendo-se como referência o total de positivos para cada alérgeno em particular. Nela observamos freqüências significantemente menores entre as crianças mais jovens. Não houve diferenças para a presença de IgE específica para gato, epitélio de

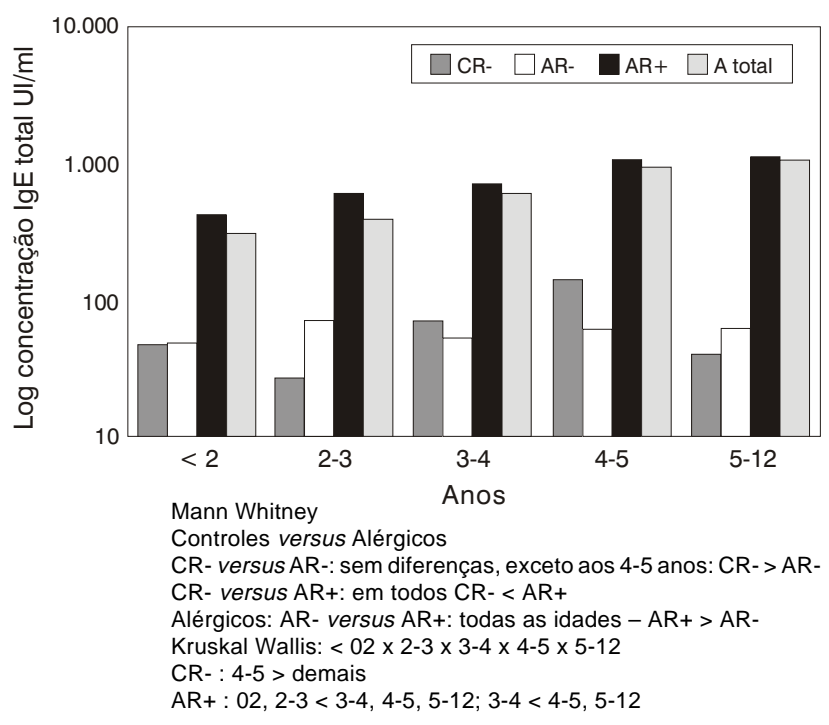

Figura 1- Níveis médios de IgE sérica total (Log concentração $\mathrm{UI} / \mathrm{ml}$ ) dos pacientes do grupo controle com IgE sérica específica (RAST) negativo (CR-) ou do grupo alérgico com RAST negativo (AR-), positivo $(A R+)$ e total (A total) 
Tabela 3 - IgE total sérica (média geométrica) dos pacientes de acordo com o resultado do RAST em cada faixa etária

\begin{tabular}{|c|c|c|c|c|c|c|c|c|}
\hline \multirow{3}{*}{$\begin{array}{c}\text { Faixa etária } \\
\text { (anos) }\end{array}$} & \multirow{2}{*}{\multicolumn{2}{|c|}{$\begin{array}{l}\text { Controles } \\
\text { RAST negativo }\end{array}$}} & \multicolumn{6}{|c|}{ Alérgicos } \\
\hline & & & \multicolumn{2}{|c|}{ RAST negativo } & \multicolumn{2}{|c|}{ RAST positivo } & \multicolumn{2}{|c|}{ Total } \\
\hline & $\mathbf{n}$ & $\mathbf{U I} / \mathbf{m l}$ & $\mathbf{n}$ & $\mathrm{UI} / \mathrm{ml}$ & $\mathbf{n}$ & UI/mI & $\mathbf{n}$ & $\mathrm{UI} / \mathbf{m l}$ \\
\hline$<2(a)$ & 10 & 46,4 & 24 & 47,0 & 53 & 417,7 & 77 & 302,1 \\
\hline $2-3(b)$ & 10 & 26,4 & 31 & 69,2 & 47 & 586,5 & 78 & 380,9 \\
\hline $3-4(c)$ & 6 & 69,3 & 16 & 51,9 & 86 & 692,4 & 102 & 591,9 \\
\hline $4-5(d)$ & 9 & 138,3 & 10 & 60,1 & 69 & 1036,7 & 79 & 913,1 \\
\hline $5-12(e)$ & 9 & 39,4 & 5 & 60,7 & 106 & 1089,2 & 111 & 1043,2 \\
\hline
\end{tabular}

Mann-Whitey; controles x alérgicos: controles x RAST negativo, sem diferenças, exceto em d (controle > alérgicos); controles $x$ RAST positivo, em todos controles < RAST positivo; alérgicos: RAST negativo x positivo, todas idades positivo > negativo; Kruskal Wallis: $a \times b \times c \times d \times$ e; controles: $d>$ demais; alérgicos: RAST positivo: $a, b<c, d, e ; c<d$, e.

vaca, cão, cavalo e fungos (Tabela 5). Com relação aos alimentos, a sensibilização ao painel de peixes foi a de maior freqüência, sendo menor entre os mais jovens. A freqüência de sensibilização ao leite de vaca foi elevada em todas as faixas etárias (Tabela 5). Noventa e seis pacientes se mostraram sensibilizados exclusivamente a alérgenos alimentares ou inalantes (Tabela 6). Ao compararmos os dois grupos, verificamos que a sensibilização aos alimentos predominou nos primeiros anos de vida, e a de inalantes, em faixas etárias mais tardias.

Tabela 4 - Distribuição dos pacientes segundo a positividade aos diferentes alérgenos comparando-se ao total geral (\%) e aos com exames positivos (\%). Dados de controles não-alérgicos

\begin{tabular}{|c|c|c|c|c|}
\hline \multirow[b]{2}{*}{ Alérgeno } & \multicolumn{2}{|c|}{ Atópicos $(n=457)$} & \multicolumn{2}{|c|}{ Controles $(n=62)$} \\
\hline & $\begin{array}{c}\text { RAST } \\
\text { positivo }\end{array}$ & $\begin{array}{l}\% \\
\text { total }\end{array}$ & $\begin{array}{c}\text { RAST } \\
\text { positivo }\end{array}$ & $\begin{array}{l}\% \\
\text { total }\end{array}$ \\
\hline D. pteronyssinus & 310 & $67,8^{*}$ & 9 & 14,5 \\
\hline D. farinae & 304 & $66,5^{*}$ & 11 & 17,8 \\
\hline B. tropicalis & 261 & $57,1 *$ & 12 & 19,4 \\
\hline Barata & 157 & $34,4 *$ & 6 & 9,7 \\
\hline Gato & 56 & 12,2 & 5 & 8,1 \\
\hline Gramíneas & 49 & $10,7 *$ & 3 & 4,8 \\
\hline Epitélio de vaca & 52 & $11,4 *$ & 4 & 6,5 \\
\hline Cão & 37 & $8,1^{*}$ & 2 & 3,2 \\
\hline Cavalo & 21 & 4,6 & 0 & 0,0 \\
\hline Fungos & 14 & 3,1 & 0 & 0,0 \\
\hline Peixe & 138 & $30,2 *$ & 7 & 11,3 \\
\hline Ovo & 112 & $24,5 *$ & 3 & 4,8 \\
\hline Leite de vaca & 93 & $20,3 *$ & 2 & 3,2 \\
\hline Trigo & 92 & $20,1 *$ & 5 & 8,1 \\
\hline Amendoim & 67 & $14,7^{*}$ & 3 & 4,8 \\
\hline Soja & 56 & $12,3 *$ & 3 & 4,8 \\
\hline Milho & 50 & $10,9 *$ & 3 & 4,8 \\
\hline
\end{tabular}

Qui-quadrado; controles < alérgicos. ${ }^{*} p<0,05$.
De acordo com a queixa principal de acompanhamento (Tabela 7), verificamos diferentes níveis de positividade para os alérgenos avaliados. Entre as crianças com alergia respiratória e dermatite atópica, houve maior freqüência de positividade aos alérgenos inalantes. Entretanto, entre as com alergia respiratória, $38,8 \%$ eram sensibilizadas a peixe. Proporção menor foi observada entre crianças com dermatite atópica. Entre as com alergia alimentar, a sensibilização foi mais freqüente ao leite de vaca, ovo, trigo, peixe e soja. Apesar disso, neste grupo, documentou-se índice significativo de sensibilização aos ácaros da poeira doméstica e, em especial, ao epitélio de vaca (Tabela 7). Nos lactentes sibilantes, observou-se menor prevalência de sensibilização, com predomínio dos alérgenos inalantes (ácaros e epitélio de vaca).

A sensibilização a mais de um alérgeno foi observada em $85 \%$ dos pacientes, sobretudo entre os mais velhos. Entre as várias combinações, encontramos como associações mais freqüentes a dos três ácaros, a do leite de vaca com epitélio de vaca e a concomitância de positividade entre ácaros, barata e peixe. Não houve diferenças no padrão de sensibilização segundo a região de origem dos pacientes (dados não apresentados).

\section{Discussão}

Níveis séricos elevados de IgE têm sido apontados como marcadores de doença atópica. Entretanto, várias situações clínicas, além das doenças alérgicas, podem cursar com elevação dos níveis séricos de IgE total - por exemplo, as helmintíases intestinais e o tabagismo ativo. Estudos prospectivos em que se determinou o nível de IgE total em sangue de cordão permitiram identificar risco maior de desenvolvimento de asma e de doenças alérgicas entre os recém-nascidos com níveis superiores a 0,9 UI/m/ ${ }^{15}$. Em estudo prévio, em que se tentou estabelecer valores de 
Tabela 5 - Pacientes de acordo com a presença de IgE específica (RAST) aos diferentes alérgenos testados. Dados expressos (\%) em relação ao total de positivos para cada categoria analisada

\begin{tabular}{|c|c|c|c|c|c|c|c|c|c|c|c|c|c|}
\hline \multirow[t]{2}{*}{ Alérgeno } & \multicolumn{2}{|c|}{$\begin{array}{c}<2 \text { anos } \\
\text { (a) }\end{array}$} & \multicolumn{2}{|c|}{$\begin{array}{c}\text { 2-3 anos } \\
\text { (b) }\end{array}$} & \multicolumn{2}{|c|}{$\begin{array}{c}\text { 3-4 anos } \\
\text { (c) }\end{array}$} & \multicolumn{2}{|c|}{$\begin{array}{c}\text { 4-5 anos } \\
\text { (d) }\end{array}$} & \multicolumn{2}{|c|}{$\begin{array}{c}\text { 5-12 anos } \\
\text { (e) }\end{array}$} & \multicolumn{2}{|c|}{ Total } & \multirow[t]{2}{*}{$\begin{array}{c}\text { Qui-quadrado/ } \\
\text { Fisher }\end{array}$} \\
\hline & $\mathbf{n}$ & $\%$ & $\mathbf{n}$ & $\%$ & $\mathbf{n}$ & $\%$ & $\mathbf{n}$ & $\%$ & $\mathbf{n}$ & $\%$ & $\mathbf{n}$ & $\%$ & \\
\hline D. pteronyssinus & 23 & 7,6 & 44 & 14,6 & 67 & 22,3 & 59 & 19,6 & 108 & 35,9 & 301 & 66,7 & $\mathrm{a}<\mathrm{b}<\mathrm{c}=\mathrm{d}<\mathrm{e}$ \\
\hline D. farinae & 17 & 5,8 & 45 & 15,5 & 66 & 22,7 & 56 & 19,2 & 107 & 36,7 & 291 & 64,5 & $\mathrm{a}<\mathrm{b}<\mathrm{c}=\mathrm{d}<\mathrm{e}$ \\
\hline B. tropicalis & 11 & 4,4 & 34 & 13,7 & 52 & 20,9 & 52 & 20,9 & 100 & 40,2 & 249 & 55,2 & $\mathrm{a}<\mathrm{b}<\mathrm{c}=\mathrm{d}<\mathrm{e}$ \\
\hline Barata & 6 & 4,1 & 11 & 7,4 & 28 & 18,9 & 38 & 25,7 & 65 & 43,9 & 148 & 32,8 & $\mathrm{a}=\mathrm{b}<\mathrm{c}<\mathrm{d}<\mathrm{e}$ \\
\hline Gato & 4 & 7,4 & 11 & 20,4 & 8 & 14,8 & 9 & 16,7 & 22 & 40,8 & 54 & 12,0 & $\mathrm{a}=\mathrm{b}=\mathrm{c}=\mathrm{d}=\mathrm{e}$ \\
\hline Epitélio de vaca & 13 & 28,9 & 6 & 13,3 & 7 & 15,6 & 11 & 24,4 & 8 & 17,8 & 45 & 10,0 & $\mathrm{a}=\mathrm{b}=\mathrm{c}=\mathrm{d}=\mathrm{e}$ \\
\hline Gramíneas & 1 & 2,2 & 1 & 2,2 & 8 & 17,8 & 13 & 28,9 & 22 & 48,9 & 45 & 9,9 & $\mathrm{a}=\mathrm{b}=\mathrm{c}=\mathrm{d}<\mathrm{e}$ \\
\hline Cão & 3 & 8,5 & 6 & 17,1 & 4 & 11,5 & 9 & 25,7 & 13 & 37,2 & 35 & 7,8 & $\mathrm{a}=\mathrm{b}=\mathrm{c}=\mathrm{d}=\mathrm{e}$ \\
\hline Cavalo & 1 & 5,3 & 2 & 10,5 & 4 & 21,1 & 5 & 26,3 & 7 & 36,8 & 19 & 4,2 & $\mathrm{a}=\mathrm{b}=\mathrm{c}=\mathrm{d}=\mathrm{e}$ \\
\hline Fungos & 1 & 7,7 & 1 & 7,7 & 4 & 30,8 & 5 & 38,5 & 2 & 15,4 & 13 & 2,9 & $\mathrm{a}=\mathrm{b}=\mathrm{c}=\mathrm{d}=\mathrm{e}$ \\
\hline Peixe & 5 & 3,8 & 16 & 12,0 & 32 & 24,1 & 32 & 24,1 & 48 & 36,1 & 133 & 29,5 & $\mathrm{a}<\mathrm{b}<\mathrm{c}=\mathrm{d}=\mathrm{e}$ \\
\hline Leite de vaca & 27 & 26,0 & 18 & 17,3 & 17 & 16,3 & 21 & 20,4 & 21 & 20,2 & 104 & 23,1 & $\mathrm{a}=\mathrm{b}=\mathrm{c}=\mathrm{d}=\mathrm{e}$ \\
\hline Trigo & 15 & 16,7 & 6 & 6,7 & 13 & 14,4 & 23 & 25,6 & 33 & 36,7 & 90 & 20,0 & $\mathrm{~b}<\mathrm{a}=\mathrm{c}=\mathrm{d}=\mathrm{e}$ \\
\hline Amendoim & 8 & 12,7 & 4 & 6,3 & 10 & 15,9 & 19 & 30,2 & 22 & 35,0 & 63 & 14,0 & $\mathrm{a}=\mathrm{b}=\mathrm{c}<\mathrm{d}=\mathrm{e}$ \\
\hline Soja & 7 & 13,2 & 4 & 7,5 & 8 & 15,1 & 14 & 26,4 & 20 & 37,8 & 53 & 11,8 & $\mathrm{a}=\mathrm{b}=\mathrm{c}<\mathrm{d}=\mathrm{e}$ \\
\hline Milho & 8 & 16,7 & 3 & 6,3 & 8 & 16,7 & 15 & 31,3 & 14 & 29,2 & 48 & 10,6 & $\mathrm{~b}<\mathrm{d}$ \\
\hline Ovo & 29 & 26,4 & 21 & 19,1 & 17 & 15,5 & 19 & 17,3 & 24 & 21,8 & 110 & 10,0 & $\mathrm{a}=\mathrm{b}=\mathrm{c}=\mathrm{d}=\mathrm{e}$ \\
\hline
\end{tabular}

Tabela 6 - Pacientes com IgE específica exclusivamente a alérgeno inalante ou alimentar de acordo com a faixa etária

\begin{tabular}{|c|c|c|c|c|c|}
\hline \multirow{2}{*}{$\begin{array}{l}\text { Grupo } \\
\text { (anos) }\end{array}$} & \multicolumn{2}{|c|}{ Inalável (I) } & \multicolumn{2}{|c|}{ Alimento (A) } & \multirow{2}{*}{$\begin{array}{c}\text { Qui- } \\
\text { quadrado } \\
\text { I X A }\end{array}$} \\
\hline & $\mathbf{n}$ & $\%$ & $\mathbf{n}$ & $\%$ & \\
\hline$<2$ & 7 & 9,9 & 14 & 56,0 & $\mathrm{I}<\mathrm{A}$ \\
\hline $2-3$ & 13 & 18,3 & 6 & 24,0 & $\mathrm{I}=\mathrm{A}$ \\
\hline $3-4$ & 20 & 28,2 & 3 & 12,0 & $I=A$ \\
\hline $4-5$ & 11 & 15,5 & 1 & 4,0 & $I=A$ \\
\hline $5-12$ & 20 & 28,1 & 1 & 4,0 & $\mathrm{I}>\mathrm{A}$ \\
\hline Total & 71 & 100,0 & 25 & 100,0 & \\
\hline
\end{tabular}

normalidade para os níveis séricos de IgE, Mancini et al. documentaram valores de IgE total inferiores a 1,0 UI/ml em sangue de cordão. Entretanto, para as crianças maiores, os autores observaram elevação dos níveis com o avançar da idade, com grande dispersão dos valores obtidos, o que inviabilizou a elaboração de um padrão nacional para os níveis de IgE sérica ${ }^{16}$.

Lopez et al. estudaram a relação entre os níveis séricos de IgE total e sua relação com sibilância precoce em lactentes acompanhados durante o primeiro ano de vida ${ }^{17}$. Eles verificaram níveis mais elevados de IgE total em sangue de cordão dos que iriam sibilar, mas sem diferenças significantes. Os recém-nascidos foram acompanhados, e houve incremento significante dos níveis séricos de IgE com o evoluir da idade. Também houve sensibilização específica à clara de ovo (43\%), ao leite de vaca $(60 \%)$ e, em menor proporção, aos D. pteronyssinus (30\%) e D. farinae (33\%) aos 12 meses de vida ${ }^{17}$.

Neste estudo, considerando-se os valores de IgE sérica total no grupo controle, observamos uma tendência a valores mais elevados nas crianças maiores. Já no grupo de atópicos, os valores foram significantemente superiores em todas as faixas etárias, com incremento significante com o evoluir da idade (Tabela 3 e Figura 1). Um dado interessante foi que, ao dividir o grupo de atópicos com relação à presença ou não de pelo menos um $\mathrm{R}+$, verificamos que crianças com resultado negativo apresentaram valores significantemente inferiores aos daquelas com $\mathrm{R}+$ e pouco superiores aos dos controles.

Além do potencial genético, a exposição ambiental aos alérgenos é ponto fundamental para a sensibilização atópica e a expressão clínica da doença. Estudos evolutivos realizados em lactentes com sibilância indicam que a presença de IgE sérica específica a alérgenos inalantes representa um índice de alto risco para o desenvolvimento de asma em idade escolar ${ }^{18}$. Em crianças hospitalizadas por sibilância e com idade inferior a 2 anos, a presença de $\mathrm{R}+$ ao trigo, à clara de ovo e aos ácaros da poeira domiciliar esteve associada a freqüência maior de asma em idade posterior ${ }^{19}$. Apesar disso, a determinação de IgE sérica específica ainda não é exame disponibilizado na maioria dos serviços de atendimento médico, governamental ou privado. 
Tabela 7 - Pacientes sensibilizados segundo a doença de base e a presença de IgE sérica específica aos diferentes alérgenos testados

\begin{tabular}{lcccc}
\hline Alérgeno & $\begin{array}{c}\text { Lactente sibilante } \\
(\mathbf{n}=\mathbf{2 0})\end{array}$ & $\begin{array}{c}\text { Alergia alimentar } \\
(\mathbf{n}=\mathbf{1 6})\end{array}$ & $\begin{array}{c}\text { Dermatite atópica } \\
(\mathbf{n}=\mathbf{5 6})\end{array}$ & $\begin{array}{c}\text { Alergia respiratória } \\
(\mathbf{n}=\mathbf{3 4 8})\end{array}$ \\
\hline D. pteronyssinus & 40,0 & 62,5 & 80,4 & 76,7 \\
D. farinae & 35,0 & 50,0 & 78,6 & 73,6 \\
B. tropicalis & 20,0 & 43,8 & 64,3 & 69,8 \\
Barata & 15,0 & 18,8 & 37,5 & 43,9 \\
Gato & 5,0 & 12,5 & 21,4 & 12,1 \\
Gramíneas & 0 & 6,3 & 10,7 & 12,9 \\
Epitélio de vaca & 25,0 & 62,5 & 14,3 & 9,5 \\
Cão & 0 & 6,3 & 12,5 & 8,9 \\
Cavalo & 0 & 6,3 & 10,7 & 4,6 \\
Fungos & 5,0 & 6,3 & 10,7 & 2,0 \\
Peixe & 15,0 & 18,8 & 32,1 & 38,8 \\
Ovo & 15,0 & 50,0 & 30,4 & 21,8 \\
Leite de vaca & 10,0 & 68,8 & 28,6 & 16,1 \\
Trigo & 10,0 & 31,3 & 30,4 & 22,1 \\
Amendoim & 10,0 & 12,5 & 17,9 & 16,9 \\
Soja & 10,0 & 18,8 & 16,1 & 10,6 \\
Milho & 0 & 12,5 & 12,5 & 10,0 \\
\hline
\end{tabular}

Na avaliação de pacientes alérgicos, é importante ter em mente o conceito da marcha alérgica. Sabe-se que as manifestações alérgicas progridem do eczema atópico e da alergia alimentar, na criança mais jovem, para a alergia respiratória mais tardiamente, com manifestação de asma e rinoconjuntivite ${ }^{20}$. Este foi um fato considerado neste estudo. Apesar de predominarem crianças da região Sudeste, a distribuição delas, segundo a faixa etária, foi similar em todas as regiões.

Considerando-se o grupo como um todo, observamos predomínio acentuado de positividade aos alérgenos inalantes, sobretudo aos ácaros $D$. pteronyssinus $(67,8 \%), D$. farinae $(66,5 \%), B$. tropicalis $(57,1 \%)$ e alérgenos de barata $(34,4 \%)$. Tais dados são justificáveis tendo-se em consideração que $348 / 457(76,1 \%)$ pacientes tinham alergia respiratória associada. Estudos anteriores realizados em nosso meio já haviam apontado esses ácaros como os de maior prevalência de sensibilização ${ }^{4-7}$.

Outro dado que nos chamou a atenção foi o índice elevado de sensibilização aos ácaros domiciliares observado entre os pacientes com queixa de dermatite atópica. Entre crianças européias com dermatite atópica e integrantes de estudo evolutivo sobre profilaxia secundária para asma, $17 \%$ eram sensibilizadas aos ácaros do pó domiciliar e $10 \%$ aos pólens ${ }^{21}$. Além disso, a redução do escore de sintomas de dermatite atópica após a instituição de medidas de redução da exposição aos ácaros da poeira domiciliar, sobretudo em colchão, aliada ao desenvolvimento de asma por cerca de $50 \%$ dos pacientes com dermatite atópica ${ }^{22}$, reforça a participação dos ácaros como agentes etiológicos importantes da dermatite atópica.
Embora em proporções inferiores, entre os pacientes com história clínica de alergia alimentar, houve predomínio de sensibilização aos aeroalérgenos. Entre os alimentos, o leite de vaca foi o mais identificado, seguido por clara de ovo, trigo, peixe e soja (Tabela 7). Em geral, as proteínas do leite de vaca são as primeiras proteínas heterólogas da dieta com as quais os lactentes entram em contato, o que justifica a sensibilização a elas em fase precoce da vida ${ }^{23}$. Nesta população, observamos predomínio de sensibilização ao leite de vaca entre as crianças com idade inferior a 2 anos, enquanto que a sensibilização ao peixe ocorreu nas crianças mais velhas, posto que a introdução deste alimento na dieta ocorre geralmente após o primeiro ano de vida. Não detectamos diferenças na prevalência de sensibilização aos diversos alérgenos alimentares segundo a região de origem dos pacientes.

Cerca de $15 \%$ dos pacientes aqui avaliados eram monossensibilizados. A prevalência de sensibilização aos alérgenos alimentares foi mais freqüente entre os de menor idade. Entre as crianças mais velhas, predominaram os aeroalérgenos (Tabela 6 ). A exposição insidiosa a quantidades mais baixas de aeroalérgenos pode ser a justificativa para a demora maior da sensibilização aos aeroalérgenos ${ }^{20}$. Estudo prospectivo de crianças do nascimento aos 6 anos de vida documentou a queda da sensibilização a alérgenos alimentares de $10 \%$ no primeiro ano para $3 \%$ aos 6 anos. Comportamento contrário foi observado com relação aos alérgenos inalantes, que de $1,5 \%$, atingiu $8 \%$ aos 6 anos $^{24}$. Este estudo não foi prospectivo e, portanto, não permitiu verificar tal comportamento. 
A presença de IgE sérica específica a alérgenos inalantes e/ou alimentares foi significantemente maior entre os atópicos e foi relacionada a idade, oscilando entre $63,6 \%$ para menores de 24 meses e $98,2 \%$ para maiores de 60 meses. Embora tenha ocorrido positividade no grupo controle, os níveis de IgE foram mais baixos e atingiram o máximo de $37,5 \%$ de exames positivos. $\mathrm{Na}$ Tabela 4 temos a freqüência de positividade aos alérgenos testados. Houve predomínio dos alérgenos inalantes (D. pteronyssinus, $D$. farinae, $B$. tropicalis e barata) sobre os alimentares (peixe, ovo, leite de vaca e trigo). O mesmo ocorreu com os controles, embora em proporções menos significativas (Tabelas 4 e 5 ).

A bateria de alérgenos empregada na realização dos testes cutâneos de hipersensibilidade imediata não foi padronizada quanto à sua origem. Deste modo, não foi possível realizar o estudo de concordância entre os resultados dos testes cutâneos e os de IgE específica.

Da população avaliada, apenas $15 \%$ apresentaram-se com sensibilização a apenas um alérgeno. Entre os demais pacientes, observamos combinações freqüentes de sensibilização concomitante aos três ácaros, ou aos três ácaros e à barata, ou aos quatro anteriores e ao painel de peixe. A presença de reatividade cruzada entre esses alérgenos é a justificativa mais plausível. Eles apresentam em comum a tropomiosina, proteína contrátil presente tanto nos ácaros quanto na barata e nos pescados (camarão) ${ }^{25}$. Outra concomitância de positividade foi a do leite de vaca e do epitélio de vaca. Seria a presença de albumina sérica bovina a principal responsável pela reatividade cruzada entre ambos? Estudos nesse sentido devem ser realizados.

Em conclusão, este é o primeiro estudo nacional que avaliou o padrão de sensibilização a alérgenos inalantes e alimentares em crianças atópicas. Ele permitiu identificar um padrão de sensibilização similar em todas as regiões do país. Em pacientes com quadro respiratório, a realização de painel composto pelos ácaros da poeira domiciliar eventualmente acrescidos de alérgenos de gato ou cão, e, para os com alergia alimentar, o painel constituído pelos alérgenos leite de vaca, trigo, peixe, clara de ovo e soja, podem auxiliar na identificação dos pacientes sensibilizados.

\section{Agradecimentos}

Agradecemos ao Sr. Fábio Arcuri (Pharmacia do Brasil), pela doação dos kits, aos Drs. Paulo G. Leser e Roseli Dobner dos Santos, do Laboratório Fleury, pela realização dos ensaios, e aos demais integrantes do Grupo PROAL, pela coleta dos dados.

\section{Referências}

1. Solé D, Yamada E, Vana AT, Werneck G, Solano LSF, Sologuren $\mathrm{MJ}$, et al. International Study of Asthma and Allergies in Childhood (ISAAC): prevalence of asthma and asthma-related symptoms among Brazilian schoolchildren. J Investig Allergol Clin Immunol. 2001;11:123-8.
2. Strachan DP, Sibbald B, Weiland SK, Ait-Khaled N, Anabwani G, Anderson $H R$, et al. Worldwide variations in prevalence of symptoms of allergic rhinoconjunctivitis in children: the International Study of Asthma and Allergies in Childhood (ISAAC). Pediatr Allergy Immunol. 1997;8:161-76.

3. Williams H, Robertson C, Stewart A, Ait-Khaled N, Anabwani G, Anderson $\mathrm{R}$, et al. Worldwide variations in prevalence of symptoms of atopic eczema in the International Study of Asthma and Allergies in Childhood. J Allergy Clin Immunol. 1999; 103:125-38.

4. Rizzo MC, Solé D, Rizzo A, Holanda MA, Rios JBM, Wandalsen NF, et al. Etiologia da doença atópica em crianças brasileiras, estudo multicêntrico. J Pediatr (Rio J). 1995;71:31-5.

5. Santos $A B$, Chapman MD, Aalberse RC, Vailes LD, Ferriani VP, Oliver $C$, et al. Cockroach allergens and asthma in Brazil: identification of tropomyosin as a major allergen with potential cross-reactivity with mite and shrimp allergens. J Allergy Clin Immunol. 1999;104:329-37.

6. Rizzo MCV, Fernadez-Caldas E, Sole D, Naspitz CK. IgE antibodies to aeroallergens in allergic children in São Paulo, Brazil. J Investig Allergol Clin Immunol. 1997;7:242-8.

7. Sarinho E, Rizzo MC, Just E, Fernandez-Caldas E, Sole D. Sensibilização aos ácaros domésticos em crianças atópicas e não-atópicas de Recife, PE, Brasil. Rev Bras Alergia Imunopatol. 2000;23:105-10.

8. Rosário Filho NA. Pollinosis in Brazil: changing concepts. J Allergy Clin Immunol. 1990;85:819-20.

9. Vieira FM, Negreiros EB. Epidemiologia da polinose na população de algumas cidades do estado do Rio Grande do Sul. Rev Bras Alerg Imunopatol. 1989;12:73-8.

10. Halazs MR, Gonsalez SL, Solé D, Naspitz CK. Specific sensitization to Dermatophagoides pteronyssinus and cutaneous reactivity to histamine in Brazilian children. J Investig Allergol Clin Immunol. 1997; 7:98-102.

11. Tripathi A, Patterson R. Clinical interpretation of skin results. Immunol Allergy Clin N Am. 2001;21:291-300.

12. Ownby DR, Anderson JA, Jacob GL. Development and comparative evaluation of a multiple-antigen RAST as a screening test for inhalant allergy. J Allergy Clin Immunol. 1984;73:466-72.

13. Wraith K, Merret J, Roth A, Yman L, Merret TG. Recognition of food-allergic patients and their allergens by the RAST technique and clinical investigation. Clin Allergy. 1979;9:25-36.

14. Warner JO, ETAC Study Group. Early treatment of the atopic child. A double-blinded, randomized, placebo-controlled trial with cetririzine in preventing the onset of asthma in children with atopic dermatitis: 18 months' treatment and 18 months' posttreatment follow-up. J Allergy Clin Immunol. 2001;108: 929-37.

15. Croner S, Kjellman N-IM, Erikson B, Roth A. IgE screening in 1701 newborn infants and the development of atopic disease during infancy. Arch Dis Child. 1982;57:364-8.

16. Mancini I, Solé $D$, Naspitz CK. Níveis séricos de IgE total em crianças brasileiras normais no primeiro ano de vida. J Pediatr (Rio J). 1996;72:98-102.

17. Lopez N, de Barros-Mazon S, Vilela MM, Condino Neto A, Ribeiro JD. Are immunoglobulin E levels associated with early wheezing? A prospective study in Brazilian infants. Eur Respir J. 2002;20:640-5.

18. Castro-Rodriguez JA, Holberg CJ, Wright AL, Martinez FD. A clinical index to define risk of asthma in young children with recurrent wheezing. Am J Respir Crit Care Med. 2000;162:1403-6.

19. Kotaniemi-Syrjänen A, Reijonen TM, Romppanen J, Coronen K, Savolainen K, Korppi M. Allergen-specific immunoglobulin E antibodies in wheezing infants: the risk for asthma in later childhood. Pediatrics. 2003;111:e255.

20. Whan U. What drives the allergic march? Allergy. 2000;55:591-9.

21. ETAC Study Group. Allergic factors associated with the development of asthma and the influence of cetirizine in a double-blind, randomized, placebo-controlled trial: first results of ETAC. Pediatr Allergy Immunol. 1998;9:116-24.

22. Bergmann RL, Edenharter G, Bergmann KE, Forster J, Bauer CP, Whan $U$, et al. Atopic dermatitis in early infancy predicts allergic airway disease at 5 years. Clin Exp Allergy. 1998;28:965-70.

23. Kulig $M$, Bergmann $R$, Klettke $U$, Tacke $U$, Wahn $U$ and the Multicenter Allergy Study Group. Natural course of sensitization to food and inhalant allergens during the first 6 years of life. J Allergy Clin Immunol. 1999;103:1173-9. 
24. Warner AM, Bjorkstén B, Munir AKM, Moller C, Kjellman N. Childhood asthma and exposure to indoor allergens: low mite levels are associated with sensitivity. Pediatr Allergy Immunol. $1996 ; 7: 61-7$

25. Arruda LK, Ferriani VP, Vailes LD, Pomes A, Chapman MD. Cockroach allergens: environmental distribution and relationship to disease. Curr Allergy Asthma Rep. 2001;1:466-73.
Correspondência:

Dirceu Solé

Rua Mirassol, 236/72

CEP 04044-010 - São Paulo, SP

Tel.: (11) 5579.3778

E-mail: dirceus@nox.net,dirceus@ajato.com.br 